\title{
A ARTE DE ESCREVER RELAÇÕES NO CIBERESPAÇO
}

\author{
Helena Gonçalves* \\ PAULO XAVIER **
}

\section{RESUMO}

A revolução tecnológica crescente arrasta consigo uma profunda revolução para o homem e para a sua cultura. É consensual entre os informáticos a importância da representação, da simulação, da comunicação, no desenho dos programas que concebem, cuja capacidade interactiva está para além das relações numéricas das ciências da computação. Os dispositivos de simulação são cada vez mais frequentes e sofisticados, com expressivo papel na vida pessoal dos seus utilizadores e, consequentemente, nas relaçōes interpessoais e sociais. Compreender a especificidade deste meio de comunicação é o nosso propósito neste artigo.

\section{Viajar: a arte de nascer noutro lugar}

Sonhar sempre fez parte da aventura humana. Quebrar os limites da imediatez e partir, construindo contextos favoráveis à realização vivencial, faz parte do nosso quotidiano. A música, o cinema, a literatura testemunham-no à saciedade. Planear, avançando cenários conformes ao desenvolvimento favorável de projectos, é a arte de gerir, fazendo acontecer o que antes se antevê em sonho. $O$ sonho é «uma constante da vida», a reclamar espaços de emergência de um virtual viver, onde a possibilidade de recriar

\footnotetext{
* Assistente do Departamento de Ciências da Comunicaçāo da Universidade do Minho. E-mail: hgoncalves@ics.uminh.pt

** Assistente do Departamento de Ciências da Comunicação da Universidade do Minho. E-mail: pxavier@ics.uminh.pt
} 
a nossa relação com o mundo se efectiva, ensaiando e testando condições do seu sucesso ou insucesso. Encarado deste ângulo, o sonho constitui uma espécie de recarga de baterias, capaz de alimentar os desafios dos percursos vivenciais, onde sobra rotina e falta criatividade. Um exercício solitário, mas solidário, um exercício de liberdade. Espaço-tempo de interioridade, de confronto e reconciliação com a nossa identidade em busca de realizações. É a travessia da ponte, sentindo as margens.

O desenvolvimento tecnológico gerou novos contextos e abriu caminhos diferentes à actividade onírica. No seu desejo de evasão, na incessante procura da superação dos limites, o homem conta agora com a possibilidade de recriar a sua relação com o mundo físico, liberto de fronteiras e distâncias, protagonizando estórias cuja acção, personagens, espaço e tempo subvertem a conhecida ordem de interacção, originando relações fascinantes e inquietantes que não deixam de surpreender. Ted Nelson, um sonhador a quem se deve a invenção do conceito de hipertexto concebido como rede da comunicação à escala planetária, concebeu um projecto que visionava como reencontro com um paraíso perdido, em sonho revelado a um poeta.

A nossa reflexão constitui um encontro expectante com este novo plano da comunicação, onde se escrevem relações nesse eterno jogo do dar e receber, do procurar e responder, da ideal solidariedade feita de diferenças e aceitações, do eu e do outro, num plano onde a ausência dos habituais constrangimentos da interacção possibilitam outras formas e oportunidades de revelação. O que nos ocupa é o funcionamento das salas de conversação, as regras que regem as trocas relacionais entre os frequentadores destes espaços e, sobretudo, a forma como as pessoas usam este meio de comunicação e, nesse convívio, como se altera a sua mente e os seus afectos.

Trata-se de ensaiar uma leitura de alguns estilos de utilização das salas de conversação, numa atitude compreensiva de motivações dos seus frequentadores e, ao mesmo tempo, de indagação deste acto de comunicação, deste sonho acordado em comum, onde se constrói uma realidade destinada a ser partilhada pelo outro.

\section{Sempre, sempre com um pé em cada um dos mundos}

No ecrã do meu computador nada mais do que um conjunto de ícones. Os meus documentos, as pastas por onde os distribuo e pouco mais. $\mathrm{O}$ meu olhar pousa sobre aquele ícone especial: o ICQ ${ }^{1}$. «Quem estará 'ligado' neste

1 ICQ lê-se "I seek-you». Trata-se de um programa informático que permite a ligação via internet a um conjunto de servidores onde estão registados milhões de utilizadores de todo o mundo. O programa permite aos utilizadores constituír uma lista de contactos, dá 
momento?» - pergunto-me. Não resisto a fazer um duplo clique sobre ele. Espero a abertura desta «janelinha» que me liga ao mundo inteiro. Introduzo a palavra-passe e surge-me a lista dos meus 'amigos da internet' mas não vejo ninguém online. Aguardo um pouco mais porque o servidor nem sempre é expedito e finalmente aparece uma mensagem a piscar. Quem a enviou está offline neste instante mas, há poucas horas, esteve aqui no ciberespaço e pensou em mim. Leio a mensagem e esboço um sorriso. É um amigo que estranhou o meu silêncio de quase uma semana e o diz de forma que não dispensa uma resposta imediata. Que pena ele não estar ligado! Gostava tanto de lhe contar o que se passou nestes dias! Contudo, quero fazê-lo online porque quero receber as suas reacções imediatas. Agora deixo-lhe apenas uma mensagem a dizer que estou bem e que tenho novidades que lhe agradarão. Este amigo é de Viana do Castelo. Não é longe mas nunca pensámos encontrar-nos, sequer para beber um café. Um dia acontecerá, certamente.

O meu olhar afasta-se do ecrã e sai janela fora levando consigo o pensamento. Imagino esse encontro e experimento alguma dificuldade em construir o meu amigo no cenário familiar de Viana. Como será ele fisicamente? Sei a idade (que ele me disse) sei o sexo (que ele me disse também), sei qual a sua ocupação (já muito conversada entre nós) mas não sei nada da sua aparência. Será gordo? Magro? Branco? Negro? Sorridente ou contido? Posso tentar inferir a partir do que conheço da sua prosa escrita. Posso atribuir-lhe uma personalidade e, a envolvê-la, um determinado tipo de corpo, rosto e gestualidade. À medida que vários retratos vão surgindo, tomo consciência das categorias que organizam o meu conhecimento e a minha percepção do mundo social. Surpreendo-me com as diferenças entre a vivência relacional quotidiana e a forma como construímos as relações no ciberespaço. Aprendi a entender as relações interpessoais como uma forma de conhecer os seres humanos e descubro que na internet me projecto de forma activa e consciente e que entro em contacto com os meus próprios sistemas de referência.

\section{Um espaço virtual povoado de pessoas virtuais}

Na ausência dos meus amigos decido visitar uma sala de conversação. Escolho a sala \#Portugal que é sempre a mais concorrida. Reparo que estão 97 pessoas ligadas à sala nesse preciso instante e fico indeciso entre

informaçāo sobre quem está ligado num dado momento e permite a comunicaçāo por mensagens escritas bem como a conversação por conferência escrita em tempo real (Chat), a tranferência de ficheiros e o envio de entereços de páginas www. 
abordar alguém em privado ou lançar um cumprimento público para a janela comum. Digo «Olá a todos!». Recebo duas respostas. Uma de um dos anfitriões da sala e outra, em privado, de alguém com a alcunha «TREVO». Respondo também em privado, elogiando a escolha da alcunha. O TREVO pergunta-me «a/s/l?» 2 e eu hesito em responder honestamente. Desconheço totalmente aquela pessoa. Não sei sequer se é uma pessoa interessante. Não sei se essa pessoa me vai responder honestamente quando eu lhe fizer a mesma pergunta. Posso responder à questão sem muito mais (e não me estarei a expor demasiado) ou então inventar uma personagem e representá-la (quem sabe projectando-me muito mais). Decido brincar e dizer que não tenho existência física. "Sou um programa informático concebido para conversar com pessoas na internet ${ }^{3}$. Não tenho idade, sexo ou localização». A minha resposta deixa o TREVO furioso. "Diz lá!» — reclama. Tento conversar sobre a real necessidade que temos de categorizar as pessoas que conhecemos na net e descubro que aquela pessoa teria ficado muito mais tranquila se eu tivesse inventado uma personagem fácil de categorizar. Invento então uma personagem para lhe fazer a vontade e descubro que o TREVO já tinha expectativas a meu respeito. A minha alcunha CHOCOLATE sugeria-lhe que talvez fosse do sexo feminino e, na sua perspectiva, a forma como evitei identificar-me confirmava essa mesma hipótese. TREVO pensava que eu era uma rapariga e ficou surpreendido quando lhe disse que era um rapaz de 18 anos. E eu? Teria eu expectativas acerca da identidade de TREVO? Claro que sim. Mas como poderia eu vir a saber a verdade?

Num meio de comunicação onde esta se efectiva quase exclusivamente através da linguagem verbal escrita, a percepção e a categorização constróem-se partindo de menos informação. Para regular a sua interacção, as pessoas precisam de categorizar os demais, mas aqui, no ciberespaço, para categorizar é preciso procurar activamente a informação. Não é como no mundo físico, onde tão frequentemente basta olhar para ter certezas.

Mesmo assim o engano é fácil. As pessoas acreditam mais no que lêem nos olhos dos outros do que nas suas palavras escritas. Não é de admirar, pois essa capacidade de ler no olhar, nas expressōes, nos gestos, na entoa-

2 Abreviação para a pergunta "age? sex? location?". Esta é uma das primeiras perguntas (senāo mesmo a primeira) que mais frequentemente dāo início ao contacto entre dois estranhos nas salas de conversação. É simultaneamente uma busca de informação com vista à categorização e um ponto de partida para uma conversa. Trata-se de um bom exemplo das normas interaccionais específicas deste meio de comunicação.

3 SoftBots são programas informáticos também designados de agentes autónomos que são concebidos para desempenhar autonomamente funções diversas. Uma das funçōes mais conhecidas é a simulaçāo de um interlocutor humano em conversaçāo. 
ção da voz, é aperfeiçoada todos os dias desde que nascemos. Confiar na palavra escrita poderá parecer irrazoável, embora as pessoas aprendam a confiar em intuiçōes que, por vezes, nem conseguem exprimir.

Em qualquer processo de comunicação ocorre simultaneamente transmissão de informação e definição da relação entre os interlocutores. A informação é, por si só, percebida como mais ou menos credível, de acordo com princípios de verosimilhança ${ }^{4}$, e é transmitida verbalmente. Contudo, é na relação que residem os aspectos menos conscientes e talvez mais poderosos da atribuição de verdade ao dito pelo interlocutor virtual e é na definição dessa relação, no dizer, alvo de negociação constante, que intervêm simultaneamente as formas verbais e as formas não-verbais de comunicação.

É um erro desvalorizar o peso da comunicação não-verbal na conferência mediada por computador.

\section{Os emotes, ou a expressão facial na ponta dos dedos}

Poderei eu inferir a expressividade de alguém através dos emotes ${ }^{5}$ que digita? As gargalhadas virtuais :-)))) ), ou o piscar de olho ;-) correspondem efectivamente à expressão real de uma pessoa nesse momento exacto? Talvez não, mas essa não parece ser uma preocupação dominante para as pessoas que se encontram e conferenciam na internet. A expressividade por emotes é sempre produzida de forma intencional, o que nem sempre sucede com as expressões observáveis no nosso rosto. Não podemos, no entanto, afirmar que aquelas expressões são falsas ou enganadoras. Elas podem traduzir emoções reais sentidas pelo emissor.

Recordo-me das vezes que me surpreendi a sorrir para o ecrã e das não muito menos vezes que soltei, com gosto, sonoras gargalhadas, sozinho no meu escritório. Recordo-me de como procuro mostrar o meu contentamento ao meu interlocutor através de um «hahahahaha» ou de um :-))))), ainda que os mais sintéticos resumam tudo num «lol» (lots of laughs).

Contudo é importante distinguir a utilização de um «lol» e a utilização de um :-())))) )) ou de um «hahahahaha»: um «lol» não discrimina a quantidade de gargalhadas. A adição de ))) não é arbitrária. É realmente expressiva, assim como o são todas as escolhas de emotes que, nesta medida, transmitem acerca do seu emissor informação que vai para além das

4 Porque será que o TREVO não acreditou que eu era um SoftBot, se afinal eles existem?

5 Emote é a designaçāo da lingua inglesa para os símbolos compostos a partir de outros do teclado e que pretendem traduzir expressões faciais de emoção. Os símolos mais usados são :-) que expressa alegria ou satisfação e o:-( que expressa tristeza. 
expressões faciais reais. Desempenham um papel fundamental na definição da relação e na decodificação dos conteúdos verbais da comunicação.

\section{Onde os silêncios podem mesmo ser ausências}

A meio de uma conversa difícil deixo de obter resposta. Interrogo-me: «o que terei dito de errado? terei ofendido o meu interlocutor? deixei-o a pensar? está a escrever uma resposta longa e ainda não terminou? ou simplesmente a conexão falhou e perdemos o contacto?». Pergunto-lhe se me está a «ler». Tenho esperança de que me diga que sim. Na ausência de resposta, aguardo que se volte a estabelecer conexão. Passados poucos minutos, recebo um pedido de desculpas e a explicação de que a interrupção foi causada por um telefonema. Peço-lhe então que me avise sempre que ocorram interrupções causadas por factores externos.

Aprendemos, na interacção face-a-face, a usar e a interpretar os silêncios. As pausas numa conferência mediada por computador podem ser o equivalente a esses silêncios, mas, neste meio de comunicação, a sua interpretação é função de um contexto restrito. Não podemos ver o rosto ou a postura do nosso interlocutor. Não sabemos sequer se ele ainda está ali ou se nos voltou costas. Não sabemos se por razões técnicas se perdeu o contacto. Podemos investigar ou simplesmente esperar. Confiamos nas normas (como que regras de cortesia do ciberespaço) que se vão estabelecendo para regular esta forma de comunicação e sancionamos aqueles que não as cumprem.

O comportamento não se limita ao conteúdo da mensagem escrita ou sequer aos emotes utilizados. A relação define-se na interacção, com os encontros e os desencontros, com interesses e desinteresses, com atenções e desatenções. Tudo isso se sente e passa directamente do ecrã para o autoconceito do comunicante. Pode-se transparecer ligeireza e tentar fazer do virtual caricatura mas é a pessoa real, na sua complexidade, quem ali está e se projecta. $\mathrm{E}$ as emoçōes, essas, são igualmente reais.

\section{A sedução do meio}

A comunicação escrita é mais mediada cognitivamente do que outras formas de comunicação. Mais do que a comunicação face-a-face e mais do que a conversação ao telefone. Existe tempo para pensar o que dizer, tempo para preparar uma frase e tempo para a corrigir. Dificilmente se escreve algo por impulso se não se quiser. Poderemos então atribuir à conferência escrita na internet uma potencial mais valia de racionalidade e de introspecção. 
Onde se situa, então, o limite da racionalidade num ambiente onde o anonimato pode abrir alamedas para a simulação e para a dissimulação? Que medos estão salvaguardados pela inconsequência que a máscara e a distância conferem? Em cada papel representado há um equilíbrio particular de afectos e de razão, num constante vaivém que vai das motivações à construção dos esquemas do Eu.

Mas não é só na mediação cognitiva ou no anonimato que as pessoas defendem a sua margem de poder sobre o processo comunicacional. É também em cada intervenção livre de censuras. É também na leitura virtualmente despida de preconceitos, feita por quem não nos conhece o rosto, a etnia ou a classe social, a presença/ausência do corpo na relação.

Tudo isto seduz. E os utilizadores mais frequentes parecem sentir a partilha de um destino comum, de uma fascinação que se transformou em vício, com histórias que se fazem de curas e recaídas. Falam entre si como «netdependentes anónimos», não se sabe bem se com culpa ou regozijo, especialmente porque o fazem em pleno êxtase de consumo.

\section{O virtual é real}

O meio é digital mas a comunicação não é exclusivamente digital. As relações estabelecidas são dinâmicas e complexas mas forçosamente mais explícitas. A metacomunicação é frequente, porque é sentida como mais necessária e porque é mais fácil de realizar. A necessidade advém da quase ausência de canais complementares que permitam cruzar informação para conferir segurança às interpretações. A facilidade resulta da perenidade do registo escrito. Os conteúdos da comunicação, uma vez emitidos, ficam disponíveis para leituras e releituras, para recriação.

Hoje falamos sobre a forma como se escrevem relações interpessoais no espaço virtual da internet. Em breve teremos de falar sobre a forma como as pessoas se tocam nesse mesmo espaço.

Outros ambientes se adivinham com o desenvolvimento de tecnologias mais poderosas e sofisticadas, quer ao nível da capacidade de processamento de informação, quer ao nível da riqueza de dispositivos sensores e efectores na interface da máquina com o seu utilizador. Não tardará, certamente, que seres humanos possam encontrar-se sob a forma de representações corporais geradas por computador em espaços virtuais também eles sintetizados. Graças a um qualquer fato «futurista» equipado com células sensoras e diversificados mecanismos de estimulação multisensorial, a interacção será tão natural quanto possível (i.e. falando e movendo-se) e as sensações físicas experienciadas serão próximas das habituais.

Novas dimensões de verdade e de engano terão de ser equacionadas. As máscaras e os ambientes obedecerão a fantasias com limites mais vastos 
e as motivações humanas encontrarão decerto expressões e riscos desconhecidos. $\mathrm{O}$ poder do indivíduo sobre o processo comunicacional será maior, assim como a sedução exercida pelo meio.

Contudo não precisamos de esperar por esses desenvolvimentos para falarmos em realidade virtual. A comunicação escrita que podemos observar hoje nas salas virtuais de conversação ou em jogos de desempenho de papéis (MUDs ${ }^{6}$ ) tem impacto nos indivíduos. Não se trata apenas do impacto sobre a vida das pessoas no mundo físico onde se movem. Trata-se sobretudo do impacto produzido pelo discurso. $O$ discurso que é em si realidade e seio de representações sociais.

As relaçōes interpessoais não são menos reais por serem escritas. Pelo contrário! É exactamente ao serem escritas que aferem, organizam e reestruturam as representações que constituem a sua realidade. Por isso, aquilo a que chamamos virtual é bem real: quer as relações, quer o espaço onde estas se estabelecem.

\section{Fragmentos de pesquisa online}

Cinco horas da tarde de um dia cinzento, ao ritmo de fortes bátegas de chuva, nada conformes com a ordem anunciada pelo calendário - meados de Setembro, afinal ainda verão. Cenário propício à fuga, à evasão, à procura de contextos favoráveis para recriar outra relação com o mundo físico. Momento oportuno para nos ligarmos à rede, não tanto com o objectivo de explorar outros níveis de realidade à dimensão dos nossos sonhos de momento, mas para descobrir outros utilizadores e, em contexto virtual, desvendar os meandros desta forma de comunicação, observá-la de perto, adivinhando-lhe os fascínios e fraquezas.

Máquinas ligadas, conexão estabelecida, o que depressa suscita tensão é o "compacto real/virtual», difícil de gerir pela multiplicidade de registos que exige, pelos ruídos que gera no processo comunicativo. Nos escassos centímetros do monitor abrem-se janelas para o mundo exterior, mas os constrangimentos do nosso pequeno mundo, da realidade em que nos inscrevemos, interferem constantemente, perturbando a concentração no discurso que construímos com os nossos interlocutores, aqueles que acederam, em negociação preliminar, a trocar impressões sobre o uso deste meio de comunicação, as motivações de frequência do ciberespaço, a sua

6 MUD é o acrónimo correspondente a Multi User Dungeon que consiste num tipo de jogo onde os utilizadores desempenham papéis online. Esses jogos podem atingir uma duração de vários meses e são conhecidos pelo seu carácter viciante. 
avaliação das relações estabelecidas online, a gratificação e benefícios recolhidos.

Aceitando as identidades virtuais reveladas, conversámos com um quadro de empresa e uma estudante universitária, ambos jovens.

Registamos que, no primeiro caso, o ICQ é um meio de comunicação interna da empresa em que trabalha, pronunciando-se o nosso interlocutor favoravelmente quanto à sua fiabilidade e reconhecendo-lhe grandes vantagens. Reflecte sobre a necessidade do uso "racional» a que contrapōe a dependência que pode gerar, virando «um veículo de auto-exclusão da tradicional forma de comunicar com outras pessoas». Precisa que a fiabilidade a que se refere é a tecnológica, porque, no que ao relacional diz respeito, a fiabilidade depende "da mentalidade das pessoas e do uso que querem dar a este tipo de comunicação". No que ao seu caso pessoal respeita, diz: "jamais "meti» conversa com quem quer que fosse, os contactos que tenho com pessoas do exterior foram todos feitos por essas mesmas pessoas, logo a conversa flui conforme seja dado o mote do outro lado da linha... A grande vantagem que tiro do ICQ continuo a dizer que é a nível interno, o resto é puro lazer e esporadicamente.» Quisemos saber se, mesmo assim, essa conversa é gratificante e como é sentido o problema da simulação. A conversa flui ao ritmo do nosso mote: «Se não fosse gratificante já teria desistido há muito»; e sobre a fronteira entre o verdadeiro e o simulado «julgo que nunca a poderemos definir, mas de qualquer forma também nunca poderemos saber se vamos sair beneficiados ou prejudicados com essa mesma falta de definição...» Conversa adiante a comparação com a comunicação face-a-face é inevitável: «o que falta realmente é a parte humana da "coisa»...a visualização, a reacção a estímulos e até mesmo o contacto...» Sobre perigos adivinhados, pronuncia-se assim: «...como não sou pessimista vou julgar isto como quando foi a descoberta do telefone e pensar que estas novas tecnologias emergentes servem apenas para aproximar as pessoas e não o contrário..." Registamos a despedida que nos parece um precioso testemunho do compacto virtual/real que antes referimos. "Como a minha vida nāo é só falar no ICQ vou começar com as despedidas esperando que tenha tido algum contributo para o seu trabalho".

A nossa estudante do curso de Direito manifesta um estilo de utilização completamente diferente do ICQ: «é um bocado difícil saber quem está do outro lado e hoje em dia convém nāo criar situações de perigo - uso o ICQ para fazer de vez em quando um pouquinho de conversa mole. (...) para descontrair; (...) quando quero companhia... tenho mais amigos virtuais do que reais." Quisemos saber o que entendia por amigo e se a definição valia para ambos os mundos - o real e o virtual. A resposta, muito negociada $e$ assente numa base de confiança que foi preciso reafirmar, saiu assim: «um amigo é alguém por vezes diferente de mim, que gosta de partilhar parte do 
seu tempo comigo, sabe falar e ouvir, elogiar e criticar quando é necessário, sabe ver as qualidades e os defeitos e não desaparece ao primeiro sinal de desentendimento... é sobretudo alguém com que posso contar sempre (este tipo de amigo é uma espécie em vias de extinção!!! :)); (...) não, os amigos virtuais são apenas conhecidos; (...) acho que as pessoas conhecem-se é ao vivo; (...) não acredito em grandes relacionamentos via online».

Conversas curtas mas saborosas que nos deram matéria para consciencializarmos aquilo de que estamos a falar.

\section{Do que realmente falamos}

O primeiro desafio que temos de enfrentar é a descoberta do que realmente falamos. Multimedia, hipermedia e hipertexto. Hipermediatização. Realidade Virtual. Ciberespaço. Do que de forma palpável falamos é de aplicaçōes com que diariamente tropeçamos, realizações multimodais diversas e inesperadas, sempre viabilizadas pela informática, que nos surpreendem pela novidade que transportam, nos seduzem pelos resultados conseguidos. Mas com algum sabor amargo pelo que representam de filōes inexplorados e inacessíveis para muitos, de linguagens que raros dominam, de que nos vamos aproximando metaforicamente, recorrendo muitas vezes à metonímia. E fica sempre mais além das experiências feitas, para além da interactividade, uma das suas características incontestadas, e que nos remete para a atitude dialógica que o utilizador estabelece com a máquina e os menus que esta lhe oferece, permitindo-lhe uma viagem navegação cujo roteiro pode construir à medida dos seus gostos e necessidades. Porque, se é de um outro contexto de interacção e de uma outra linguagem que se trata, é também de uma outra ordem de significação, de uma construção de sentido que, por hipermediatização, nos leva ao universo virtual, ao hiperespaço de todos os possíveis. Uma navegação não isenta de sobressaltos: sem bússola, sem perfeito conhecimento das latitudes, dos ventos e marés... Onde nem faltam os piratas. Num espaço/tempo modificado, povoado de imagens contraditórias, onde se desenvolvem relações interpessoais cuja natureza é importante destrinçar, marcado pelas trocas virtualizadas, das quais ousamos esperar que propiciem a exploração agradável de diferentes níveis de realidades, experiência que nos é muitas vezes recusada na nossa civilização.

É preciso detectar fenómenos sociais e psicológicos cedo para nos prepararmos para eles, até porque o «síndrome de desorientação ou labirinto do hiperespaço» já foi identificado e deixa antever consequências menos desejáveis para os seus frequentadores. 


\section{Em conclusão ousamos perguntar}

Onde termina a aventura do fantástico, da extensibilidade da imaginação, do raciocínio e da expressão para começar o reino da excentricidade solitária que enfraquece os laços de sociabilidade e convivialidade que, julgamos, será a grande virtude imaginada destas invenções?

Em que tempos poderá democratizar-se o acesso de uma significativa maioria a estes meios, a sua alfabetização nestas linguagens, é uma interrogação que se nos coloca. O que ouvimos e sabemos é que esta é já uma realidade dos nossos dias, que nos encaminhamos para uma nova sociedade marcada por profundas transformações tecnológicas e sociais, económicas, políticas e até morais. Está em jogo uma nova visão do mundo, encaminhamo-nos para uma conjuntura em que a dimensão individual e interior dos intercâmbios irá adquirir um peso determinante. Para isso, é preciso que as pessoas disponham de ecrãs, e, mais do que isso, saibam o que fazer com eles, porque estão em causa as relaçōes sociais conhecidas, em certo sentido o conceito de sociedade.

\section{Tudo vai ser virtualizado}

Tudo vai ser virtualizado, o que significa? As realidades virtuais são modos de interpretar, símbolos de universos de referência, aí incluídos os sonhos, os projectos, os saberes. A linguagem, e a linguagem hipermédia também, serve para pensar e, neste pensamento, o homem engendra realidades virtuais, o mundo dos possíveis e impossíveis, projecta outros mundos no ecrã da sua imaginação. O homem é, portanto, uma fonte imensa de virtualidades. Se as Novas Tecnologias as ampliam e as permitem, num ambiente de saudável convivência e em seu proveito, o que é necessário é a adaptação a novas regras, o desenvolvimento de estratégias, o estudo de respostas aos desafios e controvérsias nascidas no seio dos dispositivos do progresso tecnológico. 


\section{BIBLIOGRAFIA}

Baudriallard, J. (1991), Simulacros e Simulaçāo, Relógio D’Água Editores: Lisboa.

BrocCA, F. and LEVY, M. R. (Eds.), (1995) Communication in the Age of Virtual Reality, Lawrence Erlbaum Associates: Hillsdale, New Jersey.

CURRAN, P. (1994), «Des objects virtuels aux univers virtuels», in Communications et Langages, n. ${ }^{\circ} 99$.

Dossiers de l'audovisuel (1991), "L'Odyssée du virtuel», INA, n. 40.

Hittz, S.R. and TUROFF, M. (1994), The Network Nation: Human Communication via Computer (Revised Edition), The MIT Press: Cambridge, Massachusetts.

Motro, M. (1994), "Multimédia: Technologie, technique ou culture?», in Communications et Langages, $\mathrm{n}^{\circ} 100$.

RHEINGOLD, H. (1993), The Virtual Community: Homesteading on the Electronic Frontier, Addison-Wesley Publishing Company: Reading, Massachusetts.

TURKLE, Sherry (1997), A vida no ecrã. A identidade na era da internet, Relógio D'Água Editores: Lisboa. 